almost entirely destroyed. The Executive Board responded to the appeal by recommending a number of measures to provide international aid from Unesco, the International Atomic Energy Agoncy and the U.N. Technical Assistanco Administration. The library has been addod to the list of projects for which Unesco gift coupons may be given. Universities, libraries, tochnical institutes, non-government organizations, and governments of Unesco's Member States have also boen asked to contribute. Organizations or individuals wishing to help in the restoration of the library may writo to Contro Brasiloiro de Pesquisas Fisicas, 71 avenida Vonceslas Braus, Rio do Janeiro, Brazil. All offers of books, micro-films, extracts or other documentation should be made directly to the Centre. Gifts of money may be sent in the form of Unesco Gift Coupons, about which information may be obtained from the Public Liaison Division, Unesco, Place de Fontenoy, Paris $7 \mathrm{e}$.

\section{Grants for U.K. Students}

THE 1959 Grants Year Book, the fourth to be issued by the National Union of Students (1959 Grants Yoar Book : Local Education Authority Awards to Students. Pp. 107. London: National Union of Students, 1959. 2s. 6d.), comprises a detailed guide to the values of awards paid by the Ministry of Education and the Local Education Authorities to students taking courses of higher education and to the rogulations governing those awards. These details are arranged by countios and county boroughs and there are appended notes on university and technical college awards, on training colloge awards, postgraduate awards of the Department of Scientific and Industrial Research, and other bodies. An account of the new system recently introduced in Northern Ireland is included, and there is a general survey of awards, 1958-59, based on information received since November 1958. An introduction to the Year Book urges the importance of further expansion of the teacher training colleges and stresses the need for a national scale of minor awards assessed on the same basis and principles as the major awards to eliminate tho present wide variation in minor awards for technical and similar courses. Attention is directed to the wide variations between the local education authorities in number of awards shown by the Ministry of Education's published statistics.

\section{Research in Dairying}

IT is not often realized that the milk produced in the United Kingdom nowadays amounts to about 2,200 million gallons a year and is worth about $£ 1$ million a day. An industry of such magnitudo and importance surely deserves a first-class research service. The fact that it has got such a service can be seen from the annual report of the National Institute for Research in Dairying for 1958 (pp. 154. Shinfield : National Institute for Research in Dairying, University of Reading, 1959. 4s.). It is clear from the report that the Institute is making a very thorough study of the scientific principles on which the art of dairying is based, by doing research work of a high quality on fundamental problems, such as digestion and metabolism in the ruminant, the biochemistry and physiology of milk secretion, and also on problems of an immediately practical nature such as those concerned with the growing of crops for feeding dairy cattle, the milking technique itself and many technical and engineering problems associated with the handling and processing of milk and the manufacture of milk products. The report contains an informative description of the work that is being done in each department of the Institute, and some of the more significant of the recent findings are summarized in a brief outline which gives information on about thirty of the many different items under investigation. A well-deserved tribute is paid to Prof. H. D. Kay, who retired last year after being director of the Institute for more than twenty-five years, and also to the Earl of Iveagh, who has resigned from the board after a long period of service in which he did so much for the welfare of the Institute and its staff. The report includes a detailed list of 182 papers that were published in the period under review.

\section{Mathematical Games}

Amone the many aspects of Japanese culture that have recently engaged the interest of Americans is 'origami', the ancient Japanese art of paper-folding. Several books on the subject are now available in English, an origami workshop flourishes in Manhattan and the country's first paper-folding exhibit was open to the public at Cooper Union's Museum for the Arts of Decoration in New York. (Scientific American, 201, No. 1, July 1959.)

The origins of origami are lost in early Oriental history. Folded-paper birds appear as kimono decorations in eighteenth-century Japenese prints but the art is many centuries older in both China and Japan. At one time it was considered an accomplishment of refined Japanese ladies; now its chief practitioners seom to be geisha girls and Japanese children who learn it in school. During the past twenty years there has been a marked upsurge of interest in origami in Spain and South America. Traditionally, origami is the art of folding realistic animals, birds, fish and other objects from a single sheet of paper, without cutting, pasting or decorating. The attraction of origami lies in the extraordinary realism that can be obtained with nothing more than a square of paper and pair of deft hands. A sheot is folded along geometrical lines. Suddenly it is transformed into a delicate piece of miniature semi-abstract sculpture of considerable beauty.

In viow of the geometrical aspect of paper-folding, it is not surprising that many mathematicians have boen fascinated by this art. Lewis Carroll, for example, was an enthusiastic paper-folder. The literature of recreational mathematics includes many booklets and articlos on folded-paper models, including those curious toys called flexagons. The folding of regular polygons, though not part of classic origarni. is a challenging classroom exercise. The equilateral triangle, square, hexagon and octagon are quite easy to fold, but the pentagon offers special difficulties. Paper can also be folded to produce tangents that have as their envelope various low-order curves. The parabola is particularly easy to demonstrate. Closely related to this folding procedure an interesting problem in elementary calculus can be demonstrated. The most remarkable of all origami constructions is, howevor, the bird that flaps its wings. A number of origami animals have action features : a fish that opens its mouth, a frog that hops when its back is stroked, and so on.

\section{International Combustion Symposium}

THE report of the Seventh Symposium (International) on Combustion, the first of the Inter- 